Vladimir Karanović

Universidad de Belgrado

Mirjana Sekulić

Universidad de Kragujevac

\title{
La conquista del paraíso o la utopía de Cristóbal Colón
}

Palabras clave: 1492: Conquest of Paradise, Cristóbal Colón, descubrimiento, cine e historia, utopía

\section{Introducción}

Robert Rosenstone entiende el cine histórico como un relato en el que se construye la historia y así, aunque no sea el mismo medio que la historia escrita, discute los mismos temas y problemas. El cine puede abrir un camino hacia otra manera de pensar el pasado y hacernos ver por qué debería ser significativo para la gente del presente (Rosenstone, 2001: 58). El cine no refleja sino que crea la historia en base a la sociedad que lo produce. Para Pierre Sorlin, las películas expresan las preocupaciones y tendencias de su época, es decir, dicen más de la sociedad en la que se producen que del pasado al que se refieren. Esa es la razón por la cual cada película debe ser interpretada en relación al contexto histórico y social en el que fue filmada.

El guion para la película 1492: Conquest of Paradise fue escrito por la periodista francesa Roselyn Bosch, mientras que el director fue el británico Ridley Scott. Es una película de ficción histórica enfocada en la personalidad de Cristóbal Colón, filmada con motivo de la conmemoración del quinto centenario del descubrimiento de América. Waldo Ansaldi (1992: 1) parte de la idea de que las conmemoraciones y celebraciones siempre «convocan e invocan múltiples significaciones» y en cuanto al 12 de octubre de 1992 se ha hecho una verdadera colonmanía. Según Ansaldi, el Gobierno Español se ha empeñado en borrar 
la «violencia del proceso conquistador y en postular una clave interpretativa en términos de encuentro de culturas», mientras que se han relegado otros hechos históricos importantes ocurridos en 1492: la reconquista de Granada con el destierro de los moros y la expulsión de los judíos. Los tres acontecimientos suponen violencia e intolerancia cultural. La fecha de 1992 ha sido una ocasión para abrir discusiones en torno a varios lugares comunes relacionados con el descubrimiento y la conquista de América de acuerdo con las tendencias de la historiografía reciente a cuestionar los hechos pasados vistos desde el presente, con el foco especial en los mitos de los grandes protagonistas de la Historia. Robert Rosenstone (1997: 14) propone el estudio de cómo «el medio audiovisual, sujeto a reglas dramáticas y de ficción, puede hacernos reflexionar sobre nuestra relación con el pasado», pues la naturaleza de este medio puede influir sobre la redefinición y/o ampliación del concepto de la historia. Los vacíos que se presentan en la película apuntan hacia la existencia de huecos en la Historia y en la posibilidad de una lectura posmoderna de los hechos históricos. Hay que estudiar cómo las formas del cine conectan con otros discursos de la realidad y tal vez refuerzan las ideas presentes en la sociedad que las produjo (cf. Ferro, 2008). El cine, como producción ideológica, tiene la capacidad de entretener, mientras transmite ideas y consolida relatos con una fuerte carga identitaria. Es un medio de comunicación que transmite estereotipos nacionales e ideologías junto con conocimientos históricos.

El cine es un instrumento valioso en la reelaboración de la conciencia histórica, ya que, a pesar de que dista bastante tiempo entre la película y los hechos representados, se crea una relación entre el pasado y el presente. En este sentido aparece el prólogo en la película 1492: Conquest of Paradise donde podemos leer el texto que la precede, en el cual se explica que la motivación para filmarla han sido el contexto y el momento. En este texto se enfatiza la imagen estereotipada de la España medieval como el país del miedo, la superstición y sin libertades personales, en la que aparece un espíritu diferente, quien las desafía con las ideas que trasgreden los límites de lo conocido. Ya desde el principio se insiste en la idea del progreso humano conseguido con el proyecto que llevó a cabo Cristóbal Colón.

Aunque en los años 90 se conocían los rechazos a la celebración de los 500 años desde el descubrimiento de América por parte de los indios, que se sentían colonizados y oprimidos, el director Ridley Scott asegura que no ha experimentado ningún problema con ellos y que estaban satisfechos con la visión que la película ofrece de ellos. En palabras de Scott no se percibe la preocupación por los indios 
ni por su punto de vista, se da voz a Colón y para ese fin se elige el guion escrito por Roselyn Bosch. La guionista parte de la idea de que durante un largo período hubo estereotipos sobre la personalidad de Colón como un héroe, mientras que luego se ha creado un estereotipo opuesto relacionando la figura de Colón con el genocidio cultural. Según ella, la verdad se halla entre estos dos polos opuestos. Su idea es conseguir Columbus as a character study, presentando su capacidad de imaginar el futuro y la capacidad de convertir esa imaginación en realidad, pues según ella, Colón ha cambiado el mundo. Ridley Scott (2005: 85) parece haber encontrado o reconocido las características de Cristóbal Colón en un actor, Gérard Depardieu: «a strong, physical man, driven by his emotions and instinct, a strong orator with the personality to persuade men to follow him» (85).

El eje central de la película 1492: Conquest of Paradise es la vida y el proyecto de Cristóbal Colón. Al concebir la narración del descubrimiento de América como la historia de la vida de un individuo, la película se inscribe en el cine tradicional (Rosenstone, 1997: 54). Como explica Sánchez Noriega:

En el canónico 'cine histórico' que forma parte del cine comercial se prefiere la dramatización espectacular que pone en escena personajes atormentados, pasiones desatadas y heroísmos sobrehumanos a la consideración de factores sociales, ideológicos o económicos que expliquen los cambios sociales o los sucesos del devenir de la Historia. Los procesos sociales de protagonismo colectivo quedan en un segundo plano, ocultados por las gestas individuales de personajes mistificados por la costra de las leyendas o por el anecdotario de exitosa divulgación. (Sánchez, 2008: 87-88)

\section{La estructura mítica del viaje}

Hablando del tema del descubrimiento de América no se puede prescindir de la idea de viaje que está en su base. El viaje trae la noción de relatividad, ya que no existe «un lugar privilegiado desde el cual el mundo se ordenaba de una vez y para siempre» (Aínsa, 2004: 46). En la España que se presenta en la película, falta el deseo de conocer lo de más allá, se bromea con la posibilidad de aventurarse en lo ignoto, basando el rechazo en los argumentos de autoridades históricas y filosóficas conocidas hasta entonces. La imagen que se da de España es la de un país cerrado y dogmático. El único que es llevado por la idea de salir de ese mundo y de ir más allá en busca de un mundo diferente o mejor es un extranjero, Cristóbal Colón. 
Friedrich Wollfzettel (2005: 11) sugiere la idea de que la literatura de viaje está basada en una estructura mítica o iniciática. Se refiere a la tradición narratológica en la cual el mito tiene un sentido más estructural que folclórico, es decir, se puede considerar como el principio organizador de un relato de viaje. El viaje supone la partida o el desprendimiento del mundo familiar, mientras que la vuelta, otro elemento obligatorio de su estructura, supone el enriquecimiento del viajero y la adquisición de una nueva visión del mundo. Entre la ida y la vuelta se hallan la iniciación, el paso por los obstáculos y su superación. Viajar, aquí significa descubrir, pero no solo en el sentido de descubrir el mundo exterior, sino también en sentido de transformación del yo descubridor, puesto que se establece una conexión entre el mundo exterior y el yo en este proceso de iniciación.

En el caso de Colón, primero existe el deseo, imprescindible como base para realizar los cambios posteriores. El deseo es lo que motiva al viajero a dar un paso adelante y que transgreda los límites impuestos en varios niveles. El deseo de Colón además choca con varios obstáculos antes de partir, así que su iniciación, podríamos decir, empieza mucho antes que el viaje. Celina Farés en la reseña del libro de Paul Veyne Cómo se escribe la bistoria. Foucault revoluciona la bistoria, escribe:

El cambio no se da por la ideología, ni por la convicción individual, se da por la actualización del deseo. Las únicas potencialidades que un individuo puede hacer realidad son las que están prefiguradas en su entorno y que el individuo actualiza por el hecho de interesarse por ellas. El deseo es lo que explica el cambio, si no nunca pasaría nada. (Farés, 2003: 217)

La superación de los obstáculos, en la Universidad de Salamanca y en la corte de los Reyes, se debe tanto a la capacidad de Colón para convencer a la reina Isabel, como al mismo entorno de la reina, que parece ser propiciado para ambiciones y visiones.

\section{El primer encuentro de dos culturas - el choque}

En la interpretación del sentido del viaje como el elemento clave se presenta el primer encuentro con el espacio nuevo y desconocido, con otro pueblo y su cultura (Nucera, 2002: 243). Las primeras impresiones sobre el Otro pueden fijarse hasta el final del viaje o estar revisadas durante el tiempo transcurrido en el país extranjero. 
Aunque en la historia el año 1492 está marcada por el descubrimiento, en realidad hay que hablar sobre el encuentro de dos culturas, puesto que descubrir conlleva implicaciones ideológicas de relación de subordinación del que ha sido descubierto, mientras que el encuentro significa igualdad. La superioridad e inferioridad dependen del punto de vista y de la actitud, y en la historia escrita solemos ver la perspectiva española (excepto en los casos de las crónicas escritas por los indígenas), marcada por el sentimiento de supremacía.

Las escenas del primer encuentro de dos culturas en la película 1492: Conquest of Paradise parecen transcurrir en paz. Los indios son representados como curiosos pero inocentes. Se acercan a los españoles, los extranjeros en su tierra, y los palpan para conocerlos. Parece que se invierte la habitual perspectiva sobre el descubrimiento, ya que el elemento exótico son los españoles convertidos en los objetos de la curiosidad india. Sin embargo, el hecho de que sean objetos de curiosidad no significa subordinación. Ridley Scott parece demostrar que los españoles con la calma, actitud que les impuso Colón, representan superioridad cultural y mental. Los españoles se quedan tranquilos, aunque alertas, se dejan palpar y no dan señales de asombrarse por el espectáculo que deberían haber representado los indios para ellos. El carácter maravilloso de los hechos se encuentra solo en los textos de Colón, quien se descubre como el que produce el desacuerdo entre lo visto y vivido con lo escrito.

Según López Lizarazo (2010: 114), aunque los indios parecen ser ingenuos con su manera de conocer al extranjero, ellos tienen la posición de poder, puesto que se hallan en un territorio que conocen mejor que los españoles y controlan los elementos de su entorno. Claro ejemplo de esto es la muerte de Alonso Pinzón con la cual se forja la idea de que los españoles tienen que ampliar sus conocimientos para obtener dominio de los territorios nuevos. López Lizarazo sugiere la importancia del lugar en el que ocurre el primer encuentro, porque puede decidir sobre quién controla la situación. En vez del espacio de la playa que las crónicas del descubrimiento propagaron como el lugar del encuentro, en la película éste sucede en un espacio más cerrado, con las desventajas para el intruso, que puede ser, tal y como ocurre en la película, rodeado por los indios. Entonces surge la pregunta ¿por qué el extranjero no fue capturado ni vencido sino bien acogido? A pesar de esta ventaja de los nativos, serán los españoles los que los avasallarán. Y en este momento surge la pregunta sobre la visión que Ridley Scott quiere dar con la película.

Antes cabe mencionar las implicaciones generales del concepto de lo extranjero en la cultura española a finales del siglo XV. En la película se indica el 
origen extranjero de Colón como una de las razones por las que fue rechazado su proyecto por parte de la comisión universitaria. El hombre de origen extranjero, lo mismo que otras religiones, ideas extrañas o extranjeras, no tenían lugar en la España presentada en la película de Ridley Scott. Aunque en el período del centenario del 1492 solían silenciarse otros acontecimientos históricos y culturales del mismo año, en la película aparecen en el fondo de la imagen de España. La xenofobia de ese período se presentaba en la expulsión de los judíos y los moros de la península. Si del Viejo Mundo se expulsan a los extranjeros, ¿cómo se espera un trato mejor de los representantes de raza, lengua, religión y cultura diferentes en el «nuevo mundo»? Se plantea la pregunta de si la colonización de América fue una reacción hacia lo extranjero de la mente cerrada y xenofóbica de los españoles.

La película no presenta la superación del choque del primer encuentro de dos culturas y el proceso que condujo a su convivencia, dejando un hueco entre la escena del primer encuentro y el posterior compartimiento de la cotidianeidad feliz. Los obstáculos de lengua parecen no existir y solo en una escena el indio Utapán le reprocha a Colón el hecho de que nunca ha aprendido su lengua. Es la única vez que se problematiza la importancia de lengua para el establecimiento de las relaciones interculturales y la igualdad de culturas queda negada por el hecho de que solo los indios han aprendido la lengua del Otro. Parece que se acusa a Colón de que, a pesar de sus intentos de aproximarse a los indios y tratarlos bien, esto no es posible si ni siquiera ha intentado aprender su idioma. Imponiendo la lengua española se afirmaba la superioridad de los españoles.

Otra prueba de superioridad queda relacionada con la conversión de los indios al catolicismo. Colón parece defenderse de las futuras acusaciones e insiste en que la conversión se haya de hacer por persuasión y no por fuerza. Este tema surge en una conversación entre Colón y el cacique indio en la que Colón le explica que vendrán muchos españoles para transmitir la palabra de Dios. La supuesta ingenuidad india se desvanece con las palabras reveladoras del cacique: los indios ya tienen a Dios y saben que a los españoles les interesan solo sus mujeres y el oro. La motivación oculta de Colón ya es voceada y se presagia la trágica historia futura. En comparación con el primer encuentro de las culturas española y la india, las escenas de la segunda llegada de los españoles al nuevo mundo son decepcionantes. En vez de las maravillas del paraíso descrito por Colón, los españoles hallan esqueletos y el pueblo abandonado. 


\section{La Utopía de Colón}

En Wolfzettel (2005: 14) leemos que la narración del viaje se puede interpretar como una tentativa de apoderarse del Otro por parte del viajero. Según las teorías psicoanalíticas se trata de la recuperación de una parte de sí mismo, lo que se observa en el Colón en la película. Otra cara de ese apoderamiento sería la conquista y colonización de los indios por parte de los españoles.

En el comienzo de la película, en la escena en la que mira hacia el horizonte del mar, se presenta Colón como un hombre un tanto nostálgico, que siente una carencia que se podría cumplir con algo que está más allá, donde se podría llegar con un desafío al mar. El proyecto de atravesar el mar se puede interpretar como un plan personal en sentido del intento de reiniciar su propia vida o como un plan colectivo como un comienzo nuevo para el mundo antiguo, los dos igualmente conectados con la noción de utopía.

Jean Servier (2005: 276) indica que la utopía está relacionada con un momento histórico determinado y que nace del sentimiento de la decadencia de una civilización. La visión utópica es la imagen opuesta del mundo cotidiano y se basa en la posibilidad de un mundo o un futuro mejor. Por eso supone una actitud crítica hacia el mundo existente. De hecho, la reconquista de Granada en 1492, que implica la expulsión de los moros y los judíos, le sirve a Ridley Scott en la película para crear una fuerte oposición. En vez de la intolerancia y violencia presentes en España, se propone la visión de un mundo utópico, el reino de la paz. Colón es un visionario que mira hacia el viejo continente, al cual deja atrás y va en busca de otro nuevo y mejor.

La edad de oro de las utopías está relacionada con la historia de los grandes descubrimientos ultramarinos ya que los viajes tenían como meta encontrar tierras nuevas en las cuales se hallaban los inicios de la humanidad, la pureza y la bondad o, en caso de que no se encontraran, podían restablecerse. Esto también implica la oportunidad de renacer y empezar una nueva vida. La voluntad de Colón está guiada por el deseo de encontrar un espacio de felicidad, un refugio en medio del caos y la decadencia españoles, o del Viejo Mundo en general. Esta voluntad de hierro se confirma con cada paso de la película. Incluso queda demostrada en la descripción idealizada de los indios, la cual ha generado la creencia de los europeos de que existe el paraíso terrenal.

Sin embargo, el concepto de utopía también conlleva una imposibilidad de realizar la sociedad ideal imaginada. La utopía, según Servier (2005: 278), no surge como un intento de romper con las estructuras establecidas, sino para 
relegar una situación problemática mediante la imaginación. La utopía queda encerrada en los escritos de Cristóbal Colón. Colón se da cuenta de que las islas que descubre no son el continente descrito por Marco Polo y el carácter maravilloso de los hechos descritos por Colón en sus Diarios surge del deseo de encontrar el paraíso no existente o perdido definitivamente en Europa. Colón esperaba encontrar las islas míticas con oro de la Antigüedad Clásica y en sus Diarios confirmaba que las hallaba. Fernando Aínsa (2004: 54), hablando de la geografía imaginaria, dice que el hombre siempre ha tenido «el horror al vacío» y todo lo desconocido lo llenaba con seres y ambientes imaginarios. Con el acercamiento hacia estos lugares imaginarios, los límites se movían y lo desconocido siempre se hallaba más allá de lo explorado. Aínsa destaca que con la adquisición del conocimiento de estos espacios, los elementos imaginarios y ficticios desaparecen y dejan lugar a la ciencia y descripción realista. Sin embargo, en el caso de Colón, los elementos imaginados anteriormente de acuerdo con los libros leídos, no desaparecen sino que se refuerzan en la descripción de las tierras descubiertas.

La utopía propone al viajero el olvido de su procedencia para preservar el secreto del espacio feliz. Con la pérdida de la memoria se consigue el aislamiento necesario para mantener la forma de vida (Aínsa, 2004: 52-53). Eso significa que se requiere el olvido del origen europeo, elemento ausente en la película. La película presenta la deconstrucción y el replanteamiento de la utopía, puesto que se presentan los españoles que transmiten al territorio nuevo las mismas leyes y las mismas formas de vida que existían en España.

De hecho, con la visión utópica Colón exige a todos los hombres capaces de trabajar que cooperen en la edificación de la fortaleza, promoviendo un espíritu de fraternidad y de igualdad para todos, sin dejar fuera de esta regla a los nobles. Esta actitud de negación de privilegio a la nobleza, sin embargo, choca con sus expectativas y motiva su rebelión. A diferencia de la visión utópica de Colón, otros españoles ven el nuevo mundo como el lugar en el que se van a cumplir sus propios sueños: conseguir dinero, poder, mujeres indias, es decir, una oportunidad de librarse de las convenciones sociales existentes en el viejo mundo, representación de la civilización. En esta oposición maniqueísta, Colón es el portador del bien y los demás españoles representan el mal. Sin embargo, se concluye que tanto para Colón como para los demás el nuevo mundo significa una posibilidad de evasión de la sociedad española y europea en general y a la vez una oportunidad de vivir fuera de las presiones sociales. 
La historia escrita señala que la posibilidad de la utopía desapareció con la colonización de las tierras descubiertas. Sin embargo, la película plantea la duda de si esa utopía se ha desvanecido incluso más tempranamente, con la actitud misma de Colón, cuando descubre sus motivaciones de explorar tierras nuevas en busca de oro y especias y hace de los habitantes los vasallos de los Reyes Católicos. Colón acusa a los españoles de la creación del caos, pero el representante de la máxima crueldad española, Moxica, le reprocha a él su fracaso. La promesa del paraíso por parte de Colón no se ha cumplido y el resultado es el caos, la guerra, ante la cual Colón queda callado. La película parece indagar en el origen de esta lucha y se le echa la culpa al propio Moxica, portador de la actitud de superioridad racial española y promotor de la búsqueda de oro en el nuevo mundo. Sin embargo, hay un hecho que no se puede negar: los indios, durante la guerra, parecen brutales, sanguinarios, infernales al lado de las llamas del fuego, mientras que los españoles parecen defenderse. Se demuestra el otro lado de los indios pacíficos presentados en el primer encuentro y se establece el paralelismo con las escenas del conflicto en Granada, cuando los mismos españoles fueron protagonistas de la violencia sobre los extranjeros en su país.

Podríamos decir que los españoles destruyen incluso la posibilidad de la existencia de un paraíso terrenal. Igual que los profesores de la Universidad de Salamanca, que no creían en la existencia de un mundo al final del mar tenebroso, los españoles en las tierras encontradas no tenían fe en la posibilidad de un mundo mejor sin oro y riquezas, que faltaban en aquel supuesto paraíso. Colón también contribuye a esta destrucción del paraíso y el motivo que se presenta es el deseo de agradar a la reina española con los regalos en oro y piedras preciosas. Así cobra sentido el título de la película: la conquista del paraíso. Los españoles descubren tierras para conquistarlas, mientras que el paraíso solo puede existir en libertad.

El hermano de Colón abre el tema de la esclavitud. Los indios no pueden soportar el peso del trabajo en los plantaciones, así que se necesitan esclavos negros. El sentimiento comunitario que Colón quiso infundir en la gente al repartir el trabajo entre todos ha concluido con el establecimiento de la esclavitud. La utopía parece haber existido tan solo en palabras y en la perspectiva de Colón, mientras que la realidad y los testimonios de los otros no la sostienen. Después de la vuelta a España, con las acusaciones contra Colón se levantan sospechas sobre la legitimidad de sus palabras escritas a los reyes. Según la acusación, él preside el reino del caos, la degradación y la locura, en vez de la 
promesa del paraíso. El mismo Colón es presentado como colonizador, el que exigió el trabajo duro a los indios y los españoles, castigaba la desobediencia, estableció impuestos y el sistema de esclavitud.

Cuando el padre Marchena quiere marchar del lugar sacrílego en el que se ha convertido el nuevo mundo, plantea una pregunta de sumo interés: ¿por qué Colón trata del mismo modo a los salvajes que a los cristianos? ¿Qué es lo que les ofrece Colón? Simplemente responde que les ofrece el nuevo mundo que todos desearon. Sin embargo, este mundo se ha quedado en el nivel de los sueños y de las expectativas truncadas. El mundo nuevo no es malo a priori, lo convierten en malo los españoles, puesto que traen sus viejos deseos y actitudes, es decir, el mundo nuevo no puede establecerse sobre la base de las normas del viejo. Además, los españoles no creen en la existencia de un mundo nuevo en sentido de la promesa de Colón, ya que la realidad que los rodea no estaba de acuerdo con sus expectativas del paraíso. Las tierras nuevas aparecen detrás de la niebla, pero al desaparecer la niebla, se esfuman las ilusiones sobre el paraíso terrenal. La niebla presentada en la película simbólicamente apunta hacia las ideas imaginadas y faltas de precisión de Cristóbal Colón. El paraíso existe a distancia, más allá, pero al acercarse al territorio imaginado, con el conocimiento directo de la realidad circundante, va desapareciendo, excepto en los Diario de Cristóbal Colón. El choque con la realidad en los demás españoles motiva una frustración y la consecuente rebelión en nombre de la promesa del Edén.

El paraíso y el infierno pueden ser terrenales y la gente los lleva consigo a donde vaya, piensa Cristóbal Colón. ¿Será este el reconocimiento de su fracaso y del hecho de que no se puede llevar consigo el viejo mundo al ir en busca del nuevo? Ante la acusación de la reina Isabel de que el nuevo mundo es un desastre, Colón pregunta: «iY el viejo es un éxito?»

\section{Conclusiones}

Aunque Ridley Scott en la entrevista relacionada con la película 1492: Conquest of Paradise no expresa la actitud revisionista hacia la historia, en la película misma se pueden encontrar aspectos que la clasificarían como un filme histórico posmoderno. Según Rosenstone (1997: 20), este tipo de obras revisa o reinventa la historia para crear múltiples significados, es decir, va más allá de la recreación del pasado para mostrar aspectos esenciales de los hechos. De este modo, motiva varias preguntas y dudas sobre nuestro conocimiento del proceso histórico. Ridley Scott se atiene a esto al explicar que quiere contradecir 
y corregir las actitudes negativas de los historiadores contemporáneos hacia la figura de Colón.

A pesar de las limitaciones de la película como una biografía tradicional, la obra de Ridley Scott consigue demostrar que la historia es mucho más compleja y que no se puede encerrar en lugares comunes. Aunque no pretende dar una visión contra-factual de la historia escrita y no cuestiona qué hubiera sucedido en otras circunstancias, con la introducción de algunos elementos apócrifos y anticipaciones de los hechos posteriores, consigue plantear la discusión sobre las visiones del descubrimiento y la conquista de América, especialmente sobre su significado en la historia y en relación con el presente.

\section{Bibliografía}

Aínsa, F. (2004): «El viaje como trasgresión y descubrimiento. De la Edad de Oro a la vivencia de América». En: Julio Peñate Rivero (ed.), Relato de viaje y literaturas bispánicas. Madrid: Visor libros, 45-73.

Ansaldi, W. (1992): «Cristóbal Colón, un falso palomo: entre los equívocos y la grandeza» En: Salta, 1 (23/10/2013). Centro de Estudios Filosóficos de Salta (CEFISa).

Farés, C. (2003): «Reseña de Cómo se escribe la bistoria. Foucault revoluciona la bistoria, de Paul Veyne». En: Revista Confluencia, 2, 215-219.

Ferro, M. (2008): El cine, una visión de la bistoria. Madrid: Akal.

López Lizarazo, C. A. (2010): «Lo exótico en el cine sobre la conquista de América». En: Anagramas- rumbos y sentidos de la comunicación, 8, 16, 105-116.

Nucera, D. (2002): «Los viajes y la literatura». En: Armando Gnisci (ed.), Introducción a la literatura comparada. Barcelona: Crítica, 241-289.

Rosenstone, R. (1997): El pasado en imágenes. El desafío del cine a nuestra idea de la bistoria. Prólogo de Ángel Luis Hueso. Barcelona: Ariel.

Rosenstone, R. (2001): «The historical Film: Looking at the Past in a Postliterate Age». En: Marcia Landy (ed.), The Historical Film: History and Memory in Media. New Brunswick, New Jersey: Rutgers University Press, 50-66.

Sánchez Noriega, J. L. (2008): «De la 'película histórica' al cine de la memoria». En: Gloria Camarero, Beatriz de las Heras y Vanessa de Cruz (eds.), Una ventana indiscreta. La bistoria desde el cine. Madrid: Ediciones JC, Universidad Carlos III de Madrid, 87-97. 
Scott, R. (2005), «1492: Conquest of Paradise». En: Laurence F. Knapp and Andrea F. Kulas (eds.), Ridley Scott: Interviews. University Press of Mississippi, 81-89.

Servier, J. (2005): Histoire de l'utopie. Beograd: Clio (trad. al serbio Vera Pavlovic).

Wolfzettel, F. (2005): «Relato de viaje y estructura mítica». En: Leonaro Romero Tobar y Patricia Almarcegui Elduayen (eds.), Los libros de viaje: realidad vivida y género literario. Madrid: Ediciones Akal, 10-24. 


\author{
Vladimir Karanović \\ Universitiy of Belgrade \\ Mirjana Sekulić \\ Universitiy of Kragujevac
}

\title{
The conquest of paradise or Christopher Columbus's utopia
}

Keywords: 1492: Conquest of Paradise, Christopher Columbus, discovery, film and history, utopia

The paper analyses the relationship between film and history based on the film 1492: Conquest of Paradise by Ridley Scott. It questions the importance of the context in which the movie with a historical theme is created and in that light its significance is interpreted. Based on the structural theory of myth, the article examines the elements of the mythic structure of Christopher Columbus's voyage, relating this concept to Utopia. Special emphasis is placed on the importance of the first meeting or the clash between two cultures, which determines their future relations. According to the established theoretical and critical framework, the notions of paradise as well as the figure of the foreigner are questioned. The intention of this paper is to demonstrate that in Ridley Scott's film history is much more complex and cannot be enclosed in platitudes and common places. Although it was not Scott's intention to offer a counterfactual view of recorded history, and he does not question what might have happened in other circumstances, by introducing certain apocryphal elements and foretelling later historical events, we show that he is able to start a discussion on views on the process of discovery and conquest of America and especially about their meaning throughout history and their relationship with the present. 


\author{
Vladimir Karanović \\ Univerza v Beogradu \\ Mirjana Sekulić \\ Univerza v Kragujevcu
}

\title{
Osvojitev raja ali utopija Krištofa Kolumba
}

Ključne besede: 1492: osvojitev raja, Krištof Kolumb, odkritje, film in zgodovina, utopija

Prispevek obravnava film 1492: Conquest of Paradise (1492: osvojitev raja) Ridleyja Scotta ter analizira odnos med filmom in zgodovino. Analizira pomen konteksta, na katerega se nanaša film z zgodovinsko tematiko, in glede na to interpretira njegov pomen. S pomočjo strukturalnih teorij o mitih prispevek preizpraša elemente mitične strukture potovanja Krištofa Kolumba in ta koncept poveže z utopijo. Še posebej je v ospredje postavljen pomen prvega srečanja ali trka dveh kultur, ki je odločilen za njune nadaljnje odnose. Glede na vzpostavljeni teoretični in kritični okvir sta $\mathrm{v}$ prispevku preizprašana tudi figura tujca in predstava o raju. Eden od namenov tega članka je pokazati, da je v delu Ridleyja Scotta zgodovina zelo kompleksna in se ne more omejiti na običajni prostor. Čeprav nima namena podati vizije zgodovine, ki bi bila nasprotna zgodovinskim dejstvom, in se ne vpraša, kaj bi se zgodilo $\mathrm{v}$ drugačnih okoliščinah, s tem ko vključi določene apokrifne elemente in anticipira kasnejše dogodke, odpre razpravo o različnih pogledih na odkritje in osvojitev Amerike, še posebej o njihovem zgodovinskem pomenu in odnosu do sedanjosti. 